Article

\title{
Genome-Wide Patterns of Homozygosity and Relevant Characterizations on the Population Structure in Piétrain Pigs
}

\author{
Huiwen Zhan, Saixian Zhang, Kaili Zhang, Xia Peng, Shengsong Xie, Xinyun Li, Shuhong Zhao \\ and Yunlong Ma *(D)
}

Key Laboratory of Agricultural Animal Genetics, Breeding, and Reproduction of the Ministry of Education \& Key Laboratory of Swine Genetics and Breeding of the Ministry of Agriculture, Huazhong Agricultural University, Wuhan 430070, China; wenhuizhan412@gmail.com (H.Z.); zhangsaixian@163.com (S.Z.); zk11153793935@163.com (K.Z.); pengxia418@163.com (X.P.); ssxie@sibcb.ac.cn (S.X.); xyli@mai.hzau.edu.cn (X.L.); shzhao@mail.hzau.edu.cn (S.Z.)

* Correspondence: Yunlong.Ma@mail.hzau.edu.cn; Tel.: +86-027-87282091

Received: 26 February 2020; Accepted: 11 May 2020; Published: 21 May 2020

check for updates

\begin{abstract}
Investigating the patterns of homozygosity, linkage disequilibrium, effective population size and inbreeding coefficients in livestock contributes to our understanding of the genetic diversity and evolutionary history. Here we used Illumina PorcineSNP50 Bead Chip to identify the runs of homozygosity $(\mathrm{ROH})$ and estimate the linkage disequilibrium (LD) across the whole genome, and then predict the effective population size. In addition, we calculated the inbreeding coefficients based on $\mathrm{ROH}$ in 305 Piétrain pigs and compared its effect with the other two types of inbreeding coefficients obtained by different calculation methods. A total of 23,434 ROHs were detected, and the average length of $\mathrm{ROH}$ per individual was about $507.27 \mathrm{Mb}$. There was no regularity on how those runs of homozygosity distributed in genome. The comparisons of different categories suggested that the formation of long $\mathrm{ROH}$ was probably related with recent inbreeding events. Although the density of genes located in $\mathrm{ROH}$ core regions is lower than that in the other genomic regions, most of them are related with Piétrain commercial traits like meat qualities. Overall, the results provide insight into the way in which $\mathrm{ROH}$ is produced and the identified $\mathrm{ROH}$ core regions can be used to map the genes associated with commercial traits in domestic animals.
\end{abstract}

Keywords: $\mathrm{ROH}$ islands; inbreeding coefficients; effective population size; Piétrain pigs

\section{Introduction}

The Piétrain pig originated in Belgium. It was founded by crossing local swine with Berkshire, English Large White and Bayeux pig and then was exported to other countries after 1950s. Piétrain pig has medium size, well-developed muscles and white skin with black spots. It is unavoidable to create close inbreeding during breed formation [1]. Whereas those strong inbreeding and selection shaped the Piétrain's important characteristics like high lean percentages [2]. Currently, this breed is popular around the world, and it is commonly used as terminal sire in the commercial crossing system.

Runs of homozygosity $(\mathrm{ROH})$ are consecutive homozygous segments. The autozygous regions exist due to parents descending the same haplotypes to their progeny [3]. In the process of evolution, multiple factors including mutation, migration, random genetic drift and selection pressure make genotype frequency change, which consequently contributes to change the characterization of runs of homozygosity. In animal genetics, the occurrence of homozygous segments is influenced by the locations of recessive-disease, population history as well as consanguinity levels [4]. The size of 
effective population ( $\mathrm{Ne}$ ) can also reflect the patterns of runs of homozygosity indirectly. As an important parameter of population genetics, it provides an important reference for genome architecture research.

At present, compared with other existing methods, the whole genome inbreeding coefficient based on $\mathrm{ROH}\left(F_{\mathrm{ROH}}\right)$ is considered to be the most accurate calculation method for predicting the inbreeding level of each individual $[5,6]$. In addition, the inbreeding coefficient estimated from $\mathrm{ROH}$ can be divided into recent and ancestral inbreeding events [5]. Therefore, $\mathrm{ROH}$ is applied to predict inbreeding effects in animal genetics [7-9]. In theory, the variations productized by an individual would transmit to its offspring, and then they may share identical genomic segments [4]. Therefore, $\mathrm{ROH}$ can be used to optimize mating schemes for minimizing inbreeding in livestock breeding [10,11]. In addition, $\mathrm{ROH}$ is also used to detect associations between genotype and phenotype, and to identify regions associated with traits of economic interest in farm animals [11-13].

In general, $\mathrm{ROH}$ patterns in farm animals are aligned with their breeding history. There was a significant correlation between shared short $\mathrm{ROH}$ and genomic regions under selection in a population [11]. Accordingly, those $\mathrm{ROH}$ regions are probably the results of natural selection and long-term breeding programs. In theory, the genomic regions that were shaped by selection often show a significant reduction in nucleotide diversity and increase in homozygosity around the causal mutation [4]. Therefore, the genomic regions underlying artificial selection in the process of animal breeding are often connected with the high-frequency $\mathrm{ROH}$ regions [13]. It suggested that the position of runs of homozygosity may imply the genomic segments that have been subjected to selective pressure $[14,15]$.

Previous $\mathrm{ROH}$ studies focused on human and discussed the association between homozygous and complex diseases like stomach cancer, heart diseases, schizophrenia and albinism [16-19]. The autozygosity of deleterious recessive allele can reflect the cause of recessive-disease effectively [4]. With the development of high-density Chip and sequencing technology, it becomes easier to do homozygous studies. In addition, it benefits from the development of $\mathrm{ROH}$ detection methods [20]. Accordingly, researches in the causes and patterns of homozygosity have received more attention in recent years.

The present study is based on the detection of runs of homozygosity, investigating the genomic distribution and features of $\mathrm{ROH}$ in Piétrain pig using 50k single nucleotide polymorphism (SNP) GeneChip data. We further investigated the biologic significance of high frequency ROH islands. As expected, we find that $\mathrm{ROH}$ islands are associated with some important economic traits, such as meat quality. In addition, the whole genome inbreeding coefficient based on $\mathrm{ROH}$ is assessed for prediction ability through comparison with traditional pedigree inbreeding coefficient and other genomic inbreeding coefficients. Overall, the results from this study can provide insights into the pattern of runs of homozygosity and direct its application in animal breeding.

\section{Materials and Methods}

\subsection{Data Preparation}

376 Piétrain pigs that belonged to the same generation without generation overlapping were used. All research involving animals was conducted under protocols (No. 5 proclaim of the Standing Committee of Hubei People's Congress) approved by the Standing Committee of Hubei People's Congress and the ethics committee of Huazhong Agricultural University in China. Pigs were genotyped for 50,264 SNPs spread over all chromosomes using Illumina PorcineSNP50 Bead Chip. Only SNPs on autosomes were considered in the following $\mathrm{ROH}$ analyses. All analyses were based on Sus scrofa (Pig) 11.1 reference genome version. The next step was to quality-control using PLINK software and $\mathrm{R}$ programming. The filtering parameters were as follows: (i) SNPs with a call rate less than $95 \%$ were excluded, (ii) individuals with a call rate less than 95\% were discarded, (iii) SNPs with minor allele frequency less than $5 \%$ were removed and (iv) the deviated markers $\left(p<0.1 \times 10^{-3}\right)$ were 
excluded based on Hardy-Weinberg test. Finally, we performed a relationship test and removed high-related individuals.

\subsection{Linkage Disequilibrium and Effective Population Size}

The effective population size $(\mathrm{Ne})$ was defined as the number of individuals that harbor the same distribution of allele frequencies under random genetic drift in an idealized population [21]. In theory, the prediction of $\mathrm{Ne}$ can be calculated through the linkage disequilibrium (LD) scores. With the availability of high-density chip in pigs, it was feasible to calculate the LD scores between pairwise markers. In this analysis, the LD scores $\left(r^{2}\right)$ between pairwise SNPs was calculated using PLINK v1.07. The effective population sizes $(\mathrm{Ne})$ were calculated according to the formula [22,23]:

$$
N_{e}=\frac{1}{4 c}\left(\frac{1}{E\left(r^{2}\right)}-1\right)
$$

where $c$ represents the linkage map distance in Morgans [24-26]. The physical distance to genetic distance conversion rates were calculated based on total physical chromosome length stated on Sscrofa11.1 (https://www.ncbi.nlm.nih.gov/assembly/GCF_000003025.6) and each chromosome's genetic length from the National Center for Biotechnology Information (NCBI) (https://www.ncbi.nlm. nih.gov/genome/gdv/?org=sus-scrofa). In addition, $E\left(r^{2}\right)$ was the expected value of $r^{2}$ for the distance c. In addition,

$$
t=\frac{1}{2 c}
$$

where it was the time corresponding to $c$, we recruited. In addition, $\mathrm{Ne}(t)$ reflects the effective population size at $t$ generations ago. A series of distance bin between SNPs were given as follows: $0.1,0.2,0.5,1,2$, $5 \mathrm{cM}$, allowing $5 \%$ floating range of SNPs distance, to compute $\mathrm{Ne}(t)$ before $500,250,100,50,25,10$ generations. The whole process was performed for SNPs on autosomes [27].

\subsection{Identification of Runs of Homozygosity}

Runs of homozygosity were identified for each available sample separately using PLINK v1.07 which provides a sliding window to detect autozygous fragments [28]. The minimum $\mathrm{ROH}$ length was set at $1 \mathrm{Mb}$ to exclude quite common short fragments deriving from LD. To avoid the false discovery rate, the minimum number of SNPs that contained in each $\mathrm{ROH}$ was set to 10 which derived from the density of chip. Up to one missing genotype and one heterozygous locus were allowed in a sliding window. In addition, if two SNPs within a segment are too far apart from more than $1 \mathrm{Mb}$, that segment were split in two [16]. The detected runs of homozygosity were classified by physical length as follows: 1 to $<5 \mathrm{MB}, 5$ to $<10 \mathrm{MB}$ and $\geq 10 \mathrm{MB}[7,13]$. For each category, the total number of $\mathrm{ROH}$ in each chromosome was count for all the available samples.

To explore the distribution of $\mathrm{ROH}$ across the whole genome, overlapping regions were obtained from $\mathrm{ROH}$ pools with all sampled individuals using PLINK software. To a certain overlapping region, the percentage of individuals containing that region among the whole population was calculated for every overlapping region. The empirical $P$-values were generated by ranking of the percentage values from high to low. Next, we defined core regions as $\mathrm{ROH}$ islands in the top $1 \%$ of the subjects.

\subsection{Inbreeding Coefficient}

To assess the accuracy of prediction inbreeding effects using $\mathrm{ROH}$, three types of inbreeding coefficients were calculated in this study, including Pedigree-based inbreeding coefficients $\left(F_{P E D}\right)$, ROH-based inbreeding coefficients $\left(F_{R O H}\right)$, and inbreeding coefficients based on the excess of homozygosity $\left(F_{H O M}\right)$.

Pedigree-based inbreeding coefficients $\left(F_{P E D}\right)$ were calculated for Piétrain pigs, which were born between 2014 and 2017. The pedigree data were recorded by KFNetsKing software. The total record contains 3834 individuals from 126 litters, including 305 experimental samples. They were descended 
from 34 parent stock (PS) sires and 126 PS sows. Furthermore, there were a total of 29 grandparent (GP) sires, 93 GP sows, 22 great-grandparent (GGP) sires, 59 GGP sows, 10 great-great-grandparent (GGGP) sires and 23 GGGP sows in record. Among 126 litters records, 118 litters have half sibling litter records in this population (Table S1). In order to avoid the inaccuracy caused by the absence of pedigree information, the samples without pedigree records or only having one or two generation records were excluded from analysis sets. Finally, a total of 921 samples were left to calculate $F_{P E D}$ with pedigree depth ranging from 3 to 4 generations. Pedigree-based inbreeding coefficients were estimated by the pedigreemm package in R (https://cran.r-project.org/web/packages/pedigreemm/index.html). Genomic inbreeding coefficients $\left(F_{H O M}\right)$ were calculated for 305 Piétrain pigs with genotype information using the following formula:

$$
F_{H O M}=\frac{O_{i}-E_{i}}{L_{i}-E_{i}}
$$

In which $O_{i}$ is the number of observed autosomal homozygous genotypes for individual $i$ and $E_{i}$ is the number of expected autosomal homozygous genotypes for individual $i, L_{i}$ is the total number of genotyped autosomal SNPs. Those parameters were calculated in PLINK v1.07 [28].

Genomic inbreeding coefficient based on ROHs was provided by McQuillan et al. (2008) [29], defined as the length of the autosome covered by ROHs divided by the overall length of the autosome. The formula is:

$$
F_{\mathrm{ROH}}=\sum L_{\mathrm{ROH}} / L_{\text {auto }}
$$

where $\sum L_{R O H}$ is the total length of ROHs, and $L_{\text {auto }}$ is the total length of the autosomal genome which is $2478,445 \mathrm{~kb}$ in Sus scrofa (Pig).

Spearman's correlation coefficients were calculated between all above inbreeding coefficients through pairwise comparison using SAS.

\subsection{Functional Annotation for Core Regions of $\mathrm{ROH}$}

The core regions of $\mathrm{ROH}$ were annotated to identify the known genes in those regions using the genomic database in Ensembl (http://ensemble.org). The core regions of $\mathrm{ROH}$ were also matched with previously reported pig Quantitative Trait Locus (QTL) obtained from pig Quantitative Trait Locus Database (Pig QTLdb) (https://www.animalgenome.org/cgi-bin/QTLdb/SS/index). In addition, Gene Ontology (GO) terms and Kyoto Encyclopedia of Genes and Genomes (KEGG) pathways annotations were performed using the list of genes detected in core regions of $\mathrm{ROH}$ in The Database for Annotation, Visualization and Integrated Discovery (DAVID) v6.8 tool.

\section{Results}

\subsection{Characteristics of Genotypic Data}

To investigate the pattern of homozygosity, 376 Piétrain pigs were used in chip analysis. After quality control, 4 samples were removed for low genotyping, 1788 SNPs were filtered in missingness test, 2179 markers were excluded based on HWE test and 11,616 SNPs failed in the minor allele frequency test. In addition, we calculated relationship coefficient using identity-by-descent implemented in PLINK v1.07 and 71 samples were excluded (PI_HAT $\geq 0.5$ ). Finally, a total of 305 individuals with 35,549 SNPs were available for further analysis.

\subsection{The Patterns of Linkage Disequilibrium and Past Effective Population Size}

In this analysis, the LD scores of all pairwise SNPs within a physical distance $10 \mathrm{Mb}$ on the same chromosome were calculated. As shown in Figure 1, the autosomes have similar downward trend. In addition, it can be clearly observed that the mean $r^{2}$ values decreased gradually with the increase of physical distance. 


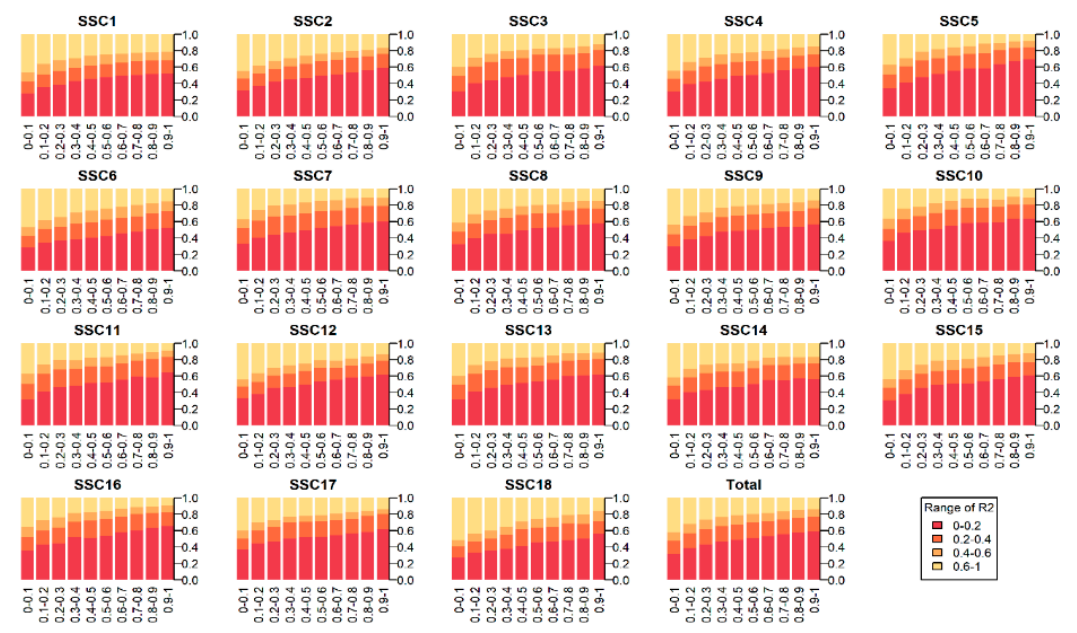

Figure 1. The tendencies of linkage disequilibrium decay across autosomes. The x-axis indicates the diverse classes of distance between SNPs pairs up to $1.0 \mathrm{Mb}$ in each chromosome and the total autosomes, the $\mathrm{y}$-axis indicates the proportion of varied $r^{2}$ classes.

According to previous studies, the effective population size of commercial pigs has gradually decreased under intensive artificial selection [30,31]. Shin et al. found that the effective population size has reduced by $99.6 \%$ through 10,000 generations in Korean Yorkshire [27]. To investigate the tendency in effective population size of Piétrain pigs from 500 generations ago to present, we set a series of bins of interval distances of pairwise SNPs. Then, a vector of LD scores-mean $r^{2}$ for each bin could be calculated. Based on the mean $r^{2}$ values, we estimated effective population size before 500, 250, 100, 50, 25, 10 generations ago. $\mathrm{Ne}$ at 500 generations ago was about 309 individuals which corresponds to the interval distances of pairwise SNPs about $0.1 \mathrm{cM}$, and then undergoes a narrowing process. While up to 10 generations ago, $\mathrm{Ne}$ has reduced to 46 individuals-a reduction of $85.1 \%$ (Table 1 ).

Table 1. The effective population size over generations for Piétrain pigs estimated from linkage disequilibrium data.

\begin{tabular}{|c|c|c|c|c|c|c|c|c|c|c|c|c|c|}
\hline \multirow[t]{2}{*}{ Chr. } & \multirow[t]{2}{*}{$\mathrm{cM} / \mathrm{Mb}$} & \multicolumn{6}{|c|}{$\begin{array}{l}\text { linkage Disequilibrium }\left(\mathrm{r}^{2}\right) \text { of Different } \\
\text { Interval Distance }(\mathrm{Kb})\end{array}$} & \multicolumn{6}{|c|}{ Estimated Ne in n Generations Ago } \\
\hline & & 100 & 200 & 500 & 1000 & 2000 & 5000 & 500 & 250 & 100 & 50 & 25 & 10 \\
\hline 1 & 0.5365 & 0.4472 & 0.3956 & 0.3188 & 0.2413 & 0.1666 & 0.0932 & 576.1 & 356.0 & 199.1 & 146.5 & 116.5 & 90.7 \\
\hline 2 & 0.8691 & 0.4464 & 0.3976 & 0.3210 & 0.2474 & 0.1721 & 0.0977 & 356.8 & 218.0 & 121.7 & 87.5 & 69.2 & 53.1 \\
\hline 3 & 0.9723 & 0.4486 & 0.4018 & 0.3248 & 0.2493 & 0.1752 & 0.1000 & 316.1 & 191.4 & 106.9 & 77.4 & 60.5 & 46.3 \\
\hline 4 & 1.0000 & 0.4482 & 0.3980 & 0.3229 & 0.2488 & 0.1753 & 0.1004 & 307.8 & 189.1 & 104.8 & 75.5 & 58.8 & 44.8 \\
\hline 5 & 1.4524 & 0.4518 & 0.4019 & 0.3264 & 0.2517 & 0.1766 & 0.1014 & 208.9 & 128.1 & 71.0 & 51.2 & 40.1 & 30.5 \\
\hline 6 & 0.9690 & 0.4477 & 0.3960 & 0.3204 & 0.2457 & 0.1718 & 0.0989 & 318.3 & 196.7 & 109.4 & 79.2 & 62.2 & 47.0 \\
\hline 7 & 1.2869 & 0.4495 & 0.4018 & 0.3253 & 0.2495 & 0.1749 & 0.1006 & 238.0 & 144.6 & 80.6 & 58.4 & 45.8 & 34.7 \\
\hline 8 & 0.9403 & 0.4480 & 0.3999 & 0.3239 & 0.2475 & 0.1731 & 0.0991 & 327.7 & 199.5 & 111.0 & 80.9 & 63.5 & 48.3 \\
\hline 9 & 0.9893 & 0.4462 & 0.3989 & 0.3238 & 0.2476 & 0.1747 & 0.1006 & 313.6 & 190.4 & 105.5 & 76.8 & 59.7 & 45.2 \\
\hline 10 & 1.8551 & 0.4508 & 0.4012 & 0.3249 & 0.2490 & 0.1755 & 0.1010 & 164.2 & 100.6 & 56.0 & 40.6 & 31.7 & 24.0 \\
\hline 11 & 1.0747 & 0.4504 & 0.4015 & 0.3248 & 0.2494 & 0.1746 & 0.0999 & 283.9 & 173.4 & 96.7 & 70.0 & 55.0 & 41.9 \\
\hline 12 & 1.8242 & 0.4482 & 0.3994 & 0.3229 & 0.2486 & 0.1744 & 0.1006 & 168.7 & 103.1 & 57.5 & 41.4 & 32.4 & 24.5 \\
\hline 13 & 0.6067 & 0.4505 & 0.4031 & 0.3255 & 0.2490 & 0.1742 & 0.0991 & 502.6 & 305.1 & 170.8 & 124.3 & 97.6 & 74.9 \\
\hline 14 & 0.7331 & 0.4515 & 0.3999 & 0.3217 & 0.2465 & 0.1714 & 0.0982 & 414.3 & 255.9 & 143.8 & 104.2 & 82.4 & 62.6 \\
\hline 15 & 0.9021 & 0.4470 & 0.4006 & 0.3242 & 0.2485 & 0.1747 & 0.1005 & 342.9 & 207.4 & 115.5 & 83.8 & 65.5 & 49.6 \\
\hline 16 & 1.1650 & 0.4498 & 0.4015 & 0.3247 & 0.2503 & 0.1758 & 0.1003 & 262.5 & 160.0 & 89.3 & 64.3 & 50.3 & 38.5 \\
\hline 17 & 1.5397 & 0.4488 & 0.3997 & 0.3234 & 0.2487 & 0.1740 & 0.0998 & 199.4 & 121.9 & 67.9 & 49.0 & 38.5 & 29.3 \\
\hline 18 & 1.1859 & 0.4476 & 0.3980 & 0.3222 & 0.2476 & 0.1733 & 0.1003 & 260.1 & 159.5 & 88.7 & 64.1 & 50.3 & 37.8 \\
\hline Total & 1.1057 & 0.4488 & 0.3998 & 0.3234 & 0.2481 & 0.1738 & 0.0995 & 309.0 & 188.9 & 105.4 & 76.4 & 60.0 & 45.8 \\
\hline
\end{tabular}




\subsection{Identification and Classification of $\mathrm{ROH}$}

In this study, a total of 23,434 $\mathrm{ROH}$ regions were identified from 305 available individuals of Piétrain pigs. We found that the total physical length of $\mathrm{ROH}$ on 18 autosomes per individual was about $507.267 \mathrm{Mb}$ on average. The density of three size categories $\mathrm{ROH}$ was presented in Figure 2 . The average length of $\mathrm{ROH}$ was $8.195 \mathrm{Mb}$, and the size of $\mathrm{ROH}$ between $1 \mathrm{Mb}$ and $5 \mathrm{Mb}$ accounts for the majority of the total $\mathrm{ROH}(50.994 \%)$. The distribution of total length of $\mathrm{ROH}$ in each chromosome was presented in Figure 3A. The total $\mathrm{ROH}$ length in chromosome 1 was about 30,553.10 Mb, which was the longest one among all chromosomes. Similarly, the mean length of $13.325 \mathrm{Mb}$ in chromosome 1 was also the largest among all chromosomes. ROHs were classified into three size classes according to the physical length: short ( 1 to $<5 \mathrm{Mb}$ ), intermediate ( 5 to $<10 \mathrm{Mb}$ ) and long $(\geq 10 \mathrm{Mb}$ ). The length of short $\mathrm{ROH}$ was $122.216 \mathrm{Mb}$ per individual, the intermediate $\mathrm{ROH} 144.041 \mathrm{Mb}$ and the long $\mathrm{ROH}$ $363.227 \mathrm{Mb}$. Correspondingly, the proportion of each class to the total number of ROHs was measured: the short ROHs account for 11,950 (50.994\%), the intermediate ROHs account for $6269(26.752 \%)$ and the long ROHs account for 5215 (22.254\%). The distribution of $\mathrm{ROH}$ regions on autosomes was shown in Figure 3B. The greatest number of ROHs across genome was located in chromosome 1 with 2293 regions.

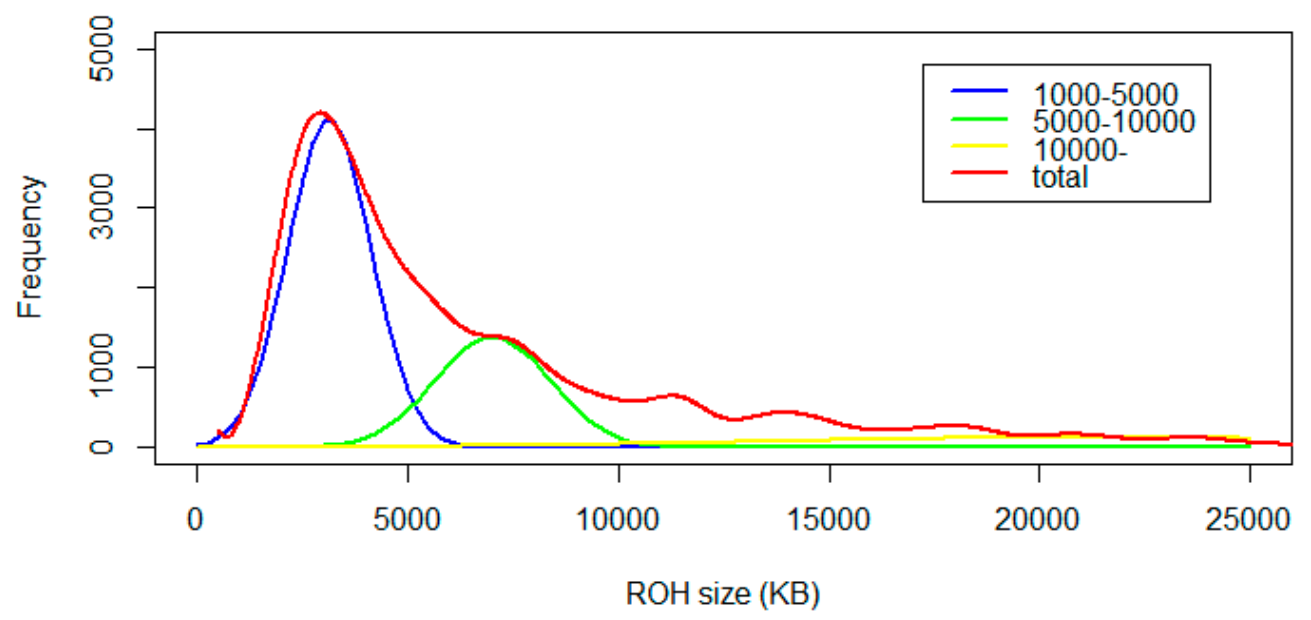

Figure 2. Density estimates of runs of homozygosity $(\mathrm{ROH})$ in three size categories. The $x$-axis indicates the size of $\mathrm{ROH}(\mathrm{Kb})$, the $\mathrm{y}$-axis indicates the value of density.

A

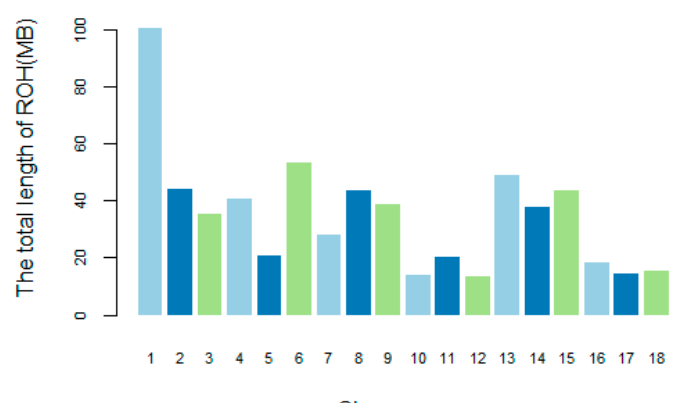

Chromesome

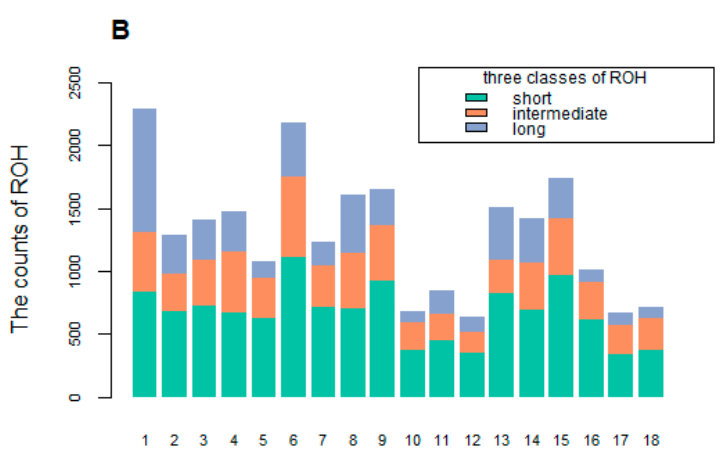

Chromesome

Figure 3. Distribution of ROH in each chromosome. (A) Total length of $\mathrm{ROH}$ on 18 autosomes. (B) Counts of three classes of $\mathrm{ROH}$ on 18 autosomes.

In this analysis, 1574 overlapping genomic regions were obtained from $\mathrm{ROH}$ pools. Moreover, 16 $\mathrm{ROH}$ regions whose coverage rate are in the top $1 \%$ were selected as the core regions. Among them, 
there are 6 regions in chromosome 1, 5 regions in chromosome 8 and 3 regions in chromosome 6 , while chromosome 15 and chromosome 18 harbored 1 region, respectively.

To further investigate these core regions, we highlighted the distribution of ROHs frequencies, allele frequencies and the gene diversity in Figure 4 . For each $100 \mathrm{~Kb}$ window, we calculated the number of individuals that were homozygous in the window and plot the distribution of homozygous SNPs frequency in chromosomes 1, 6 and 8 by black line. The distribution of the core regions was consistent with the corresponding allele frequencies. Compared with other genomic regions, there were a smaller number of genes in these regions. However, we observed several genes which were related to Piétrain specific economic traits around $\mathrm{ROH}$ regions, such as MRAP2 which was related to energy homeostasis machinery, and CLGN which was involved in the control of spermatogenesis and infertility.
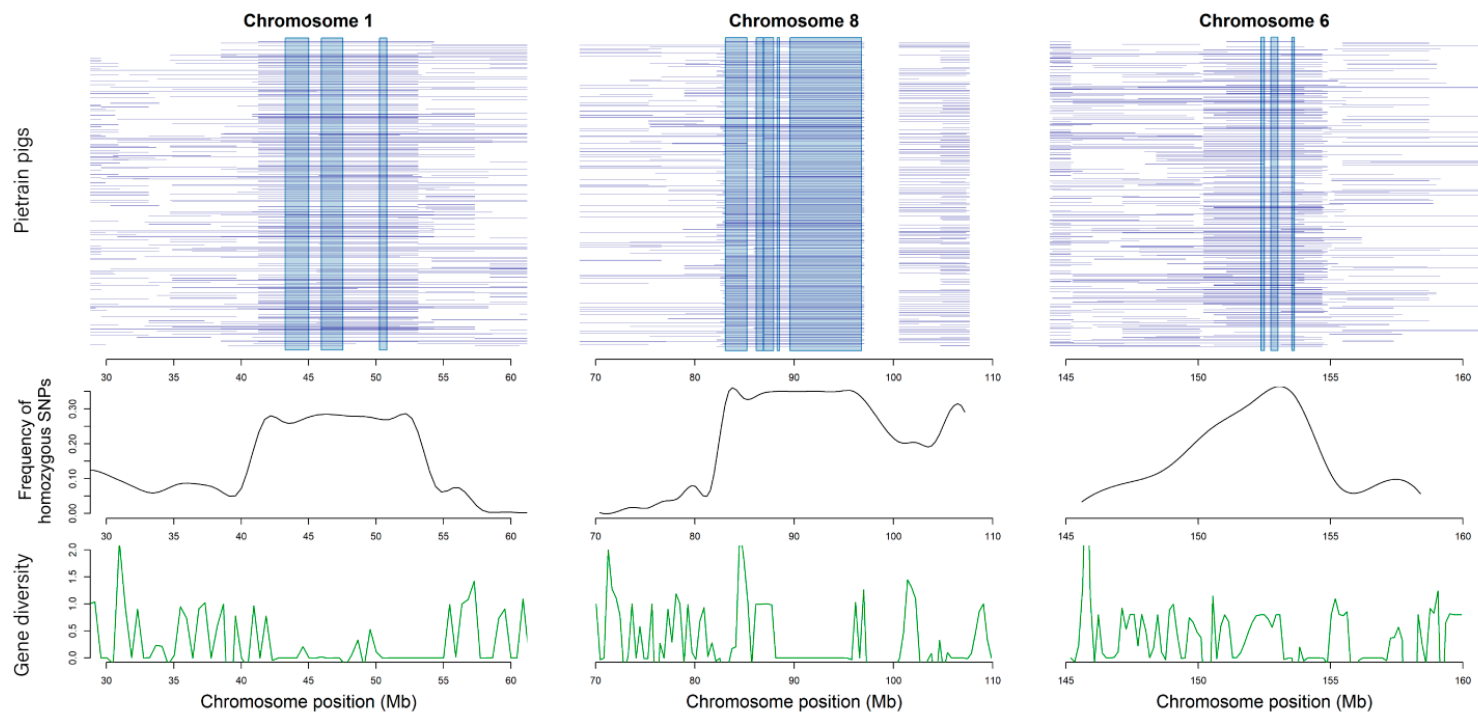

Figure 4. The distribution of $\mathrm{ROH}$ core regions in chromosome 1,8 and 6, the allele frequency and gene diversity in each SNP among the corresponding regions. Blue horizontal lines represent distribution of $\mathrm{ROH}$ of per individual. Black line represents frequency of homozygous SNPs averaged in each step of $100 \mathrm{~Kb}$. Green line represents gene diversity per SNP.

\subsection{Comparison of Different Inbreeding Coefficients}

Pedigree-based inbreeding coefficients $\left(F_{P E D}\right)$ were estimated using 921 individuals with pedigree depth ranging from 3 to 4 generations. In addition, the genomic inbreeding coefficients $\left(F_{H O M}\right.$ and $F_{R O H}$ ) were calculated using 305 individuals with genotype data. The mean value of $F_{R O H}$ based on the total length of $\mathrm{ROH}$ was 0.205 . More specifically, the mean of inbreeding coefficient based on short $\mathrm{ROH}(1$ to $<5 \mathrm{MB}$ ) was 0.049 , the mean based on the intermediate $\mathrm{ROH}$ ( 5 to $<10 \mathrm{MB}$ ) was 0.058 and long $\mathrm{ROH}(\geq 10 \mathrm{MB}) 0.147$.

To further investigate the inbreeding coefficients obtained by different calculation methods, we performed pairwise comparisons between $F_{P E D}, F_{H O M}$ and $F_{R O H}$ in samples with both pedigree information and chip data. Among them, $F_{H O M}$ and $F_{R O H}$ had a high correlation of 0.949 (p-value $=1.908 \mathrm{e}-06)$ as shown in Figure $5 \mathrm{~A}$, whereas neither $F_{H O M}$ nor $F_{R O H}$ was highly correlated with $F_{P E D}: r=0.161$ ( $p$-value $\left.=0.452\right)$ between $F_{P E D}$ and $F_{H O M}, r=0.197(p$-value $=0.357)$ between $F_{P E D}$ and $F_{R O H}$, respectively (Figure $\mathrm{S} 1$ ). These results suggested computational methods and principles applied in estimating pedigree-based inbreeding coefficients and genomic inbreeding coefficients were distinctive, which also affected the accuracy of calculation, especially in the absence or lack of pedigree information. More specifically, we expected the different categories of $\mathrm{ROHs}$ may reflect different population demography. According to previous studies, long $\mathrm{ROH}$ was related to more recent parental relatedness, which can reflect the degree of inbreeding effect $[8,11]$. To confirm this assumption, we have investigated the relationship between the inbreeding coefficients based on three 
categories of ROHs and $F_{H O M}$. The results presented in Figure $5 \mathrm{~B}$ were consistent with previous assumption, the genomic inbreeding coefficients based on the long $\mathrm{ROH}$ was strongly correlated with $F_{H O M}(r=0.910, p$-value $=2.614 \mathrm{e}-06)$. By contrast, neither short $\mathrm{ROH}$ nor intermediate $\mathrm{ROH}$ has high correlation with $F_{H O M}(r=0.038$ for short $\mathrm{ROH}$ with $p$-value $=0.860$ and $r=0.499$ for intermediate $\mathrm{ROH}$ with $p$-value $=0.014$, respectively), as shown in Figure 5C,D. The results suggested that long ROH may arise from recent inbreeding, whereas short and intermediate $\mathrm{ROH}$ have different mechanisms.

A

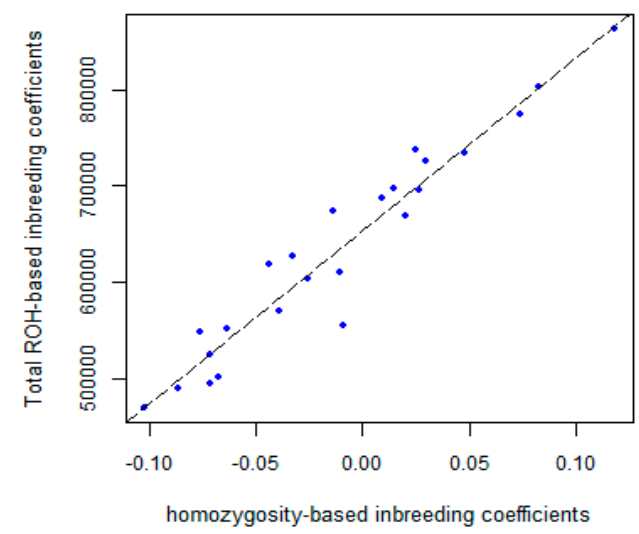

C

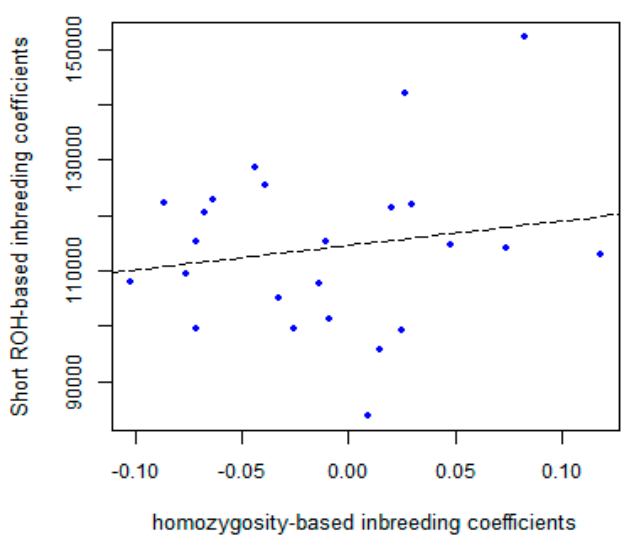

B

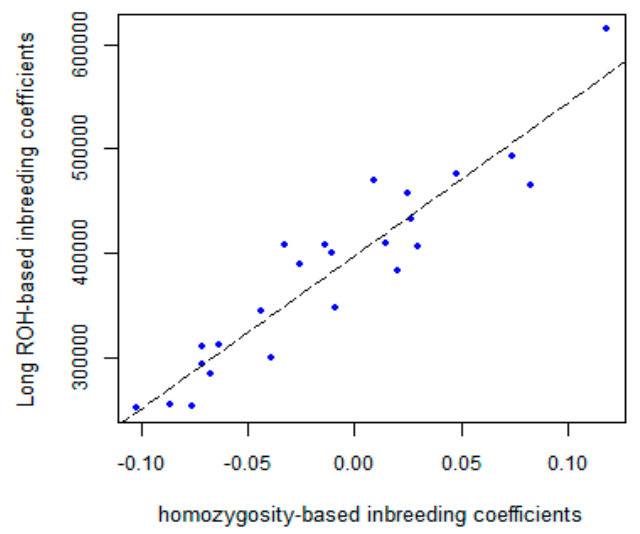

D

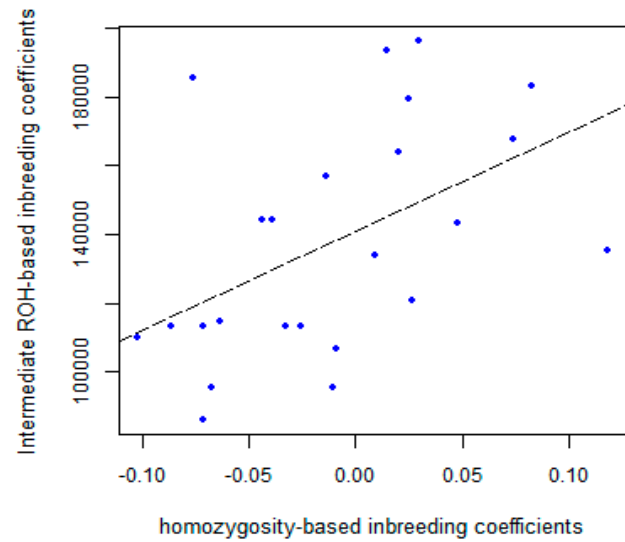

Figure 5. Relationship between $\mathrm{ROH}$-based inbreeding coefficients and homozygosity-based inbreeding coefficients. (A) shows $F_{H O M}$ and $F_{R O H}$ (total) had a high correlation $(r=0.949$, $p$-value $=1.908 \mathrm{e}-06)$. (B) shows $F_{R O H}$ (long $\left.\mathrm{ROH}\right)$ also was strongly correlated with $F_{H O M}(r=0.910$, $p$-value $=2.614 \mathrm{e}-06)$. (C) shows $F_{H O M}$ and $F_{R O H}$ (short) had a low correlation $(r=0.038$, p-value $=0.860)$. (D) shows $F_{H O M}$ and $F_{R O H}$ (intermediate) had a low correlation $(r=0.499, p$-value $=0.014)$.

\subsection{Functional Annotation for Core Regions of $\mathrm{ROH}$}

In this analysis, a total of 16 core $\mathrm{ROH}$ regions were investigated and sought for QTLs related to important production traits in pig QTLdb (Table 2). To further investigate the potential biologic significance of those core regions of $\mathrm{ROH}$, the genes that located in the core regions and in the $500 \mathrm{~Kb}$ windows around the $\mathrm{ROH}$ were annotated. The window size was determined by the LD decay. There were 127 genes around core $\mathrm{ROH}$ regions (Table S2). Among those genes, we noticed some of them were related to biologic processes and some of them were even associated with economical traits, including SLC35F1, B3GAT2, DCBLD1, LMBRD1, OMA1, MRAP2 and CLGN (Table 3). 
Table 2. A list of quantitative trait locus overlapping with the core runs of homozygosity $(\mathrm{ROH})$ regions in Piétrain pig.

\begin{tabular}{|c|c|c|}
\hline Category & Trait & QTL ID \\
\hline \multirow{7}{*}{$\begin{array}{l}\text { Meat and } \\
\text { Carcass }\end{array}$} & Anatomy & QTL:28022,QTL:8699,QTL:154422,QTL:29582,QTL:10245 \\
\hline & Fat composition & $\begin{array}{c}\text { QTL:31377,QTL:31364,QTL:31383,QTL:32083,QTL:18547, } \\
\text { QTL:101788,QTL:101825,QTL:31356,QTL:31374,QTL:101552, } \\
\text { QTL:18546,QTL:31372,QTL:31361,QTL:31368,QTL:18548, } \\
\text { QTL:101865,QTL:31360,QTL:6435,QTL:31369,QTL:18549, } \\
\text { QTL:101898,QTL:31370 }\end{array}$ \\
\hline & fatness & QTL:22293,QTL:139226 \\
\hline & Meat color & QTL:36140,QTL:36138 \\
\hline & $\mathrm{pH}$ & QTL:23051,QTL:18667,QTL:5871 \\
\hline & texture & QTL:23050,QTL:7819,QTL:7885,QTL:3864,QTL:23052 \\
\hline & Chemistry & QTL:9042 \\
\hline \multirow[t]{2}{*}{ Health } & blood parameters & $\begin{array}{l}\text { QTL:29669,QTL:29665,QTL:29663,QTL:29668,QTL:29670, } \\
\text { QTL:29666,QTL:6549,QTL:6318,QTL:29667 }\end{array}$ \\
\hline & Immune capacity & QTL:127811 \\
\hline Exterior & & $\begin{array}{c}\text { QTL:124729,QTL:17665,QTL:32743,QTL:16383,QTL:125736, } \\
\text { QTL:64738,QTL:64740,QTL:64686 }\end{array}$ \\
\hline \multirow[t]{3}{*}{ Production } & feed conversion & QTL:27977 \\
\hline & feed intake & QTL:31324 \\
\hline & Growth & QTL:22971 \\
\hline \multirow[t]{3}{*}{ Reproduction } & Litter traits & QTL:31861,QTL:122507,QTL:64741,QTL:18327 \\
\hline & Reproductive organs & QTL:18371,QTL:126623,QTL:126620 \\
\hline & Reproductive traits & QTL:7662,QTL:18326,QTL:18329,QTL:18328,QTL:18325 \\
\hline
\end{tabular}

Table 3. A list of candidate genes overlapping with the core ROH regions in Piétrain pig.

\begin{tabular}{|c|c|c|c|c|c|}
\hline Chr. & Position $(\mathrm{Kb})$ & $\begin{array}{l}\text { Length } \\
(\mathrm{Kb})\end{array}$ & $\begin{array}{l}\text { ROH Mapping } \\
\text { Frequency }^{1}\end{array}$ & Genes & Gene Function \\
\hline 1 & 53078-53113; & 35.052 & $76.38 \%$; & $M R A P 2$ & $\begin{array}{l}\text { regulate the energy homeostasis } \\
\text { machinery [32] }\end{array}$ \\
\hline 1 & 50245-50798; & 553.125 & $73.14 \%$; & B3GAT2 & $\begin{array}{l}\text { implicated in cellular migration and } \\
\text { adhesion in the nervous system [33] }\end{array}$ \\
\hline 1 & 50245-50798; & 553.125 & $73.14 \%$; & $L M B R D 1$ & $\begin{array}{l}\text { participated in compound integral } \\
\text { component of membrane [34] }\end{array}$ \\
\hline 1 & 43257-450112; & 1754.52; & $72.17 \%$ & SLC35F1 & $\begin{array}{l}\text { play count role of control heat rate and } \\
\text { cardiovascular disease [35] }\end{array}$ \\
\hline 1 & 43257-45012; & 1754.52 & $72.17 \%$ & $D C B L D 1$ & $\begin{array}{l}\text { participated in compound integral } \\
\text { component of membrane [36] }\end{array}$ \\
\hline 6 & 153543-153633; & 90.199; & $69.90 \%$ & OMA1 & $\begin{array}{l}\text { participated in compound integral } \\
\text { component of membrane [37] }\end{array}$ \\
\hline 8 & $\begin{array}{l}86943-87935 \\
86188-86896\end{array}$ & $\begin{array}{l}\text { 991.802; } \\
708.867\end{array}$ & $\begin{array}{l}68.28 \% \\
66.67 \%\end{array}$ & CLGN & $\begin{array}{l}\text { important modulator in } \\
\text { spermatogenesis and infertility [38] }\end{array}$ \\
\hline
\end{tabular}

1 ROH mapping frequency represents the percentage of individuals containing that region among the whole population.

\section{Discussion}

Runs of homozygosity are contiguous homozygous genotype fragments in the genome that are present in an individual since the identical gametes are inherited from the parents. In previous studies, Bosse et al. studied genetic patterns of $\mathrm{ROH}$ from several breeds $(n=52)$ through $60 \mathrm{~K}$ SNPchip and the smallest population (Hampshire) only contained 2 individuals [10]. Purfield et al. used multiple breeds of cattle to determine diversity of $\mathrm{ROH}$, including Angus $(\mathrm{n}=39)$, Belgian Blue $(\mathrm{n}=38)$, Hereford $(n=40)$ and Simmental $(n=58)$ using 50K SNP [13]. It was reliable that using a larger sample size to investigate the genomic characterization in Piétrain pigs in this study. Overall, runs of homozygosity are widespread in Piétrain genome, but there was no predictable position distribution. 
All detected $\mathrm{ROH}$ were divided by physical length into three categories and the short $\mathrm{ROH}$ which accounted for the largest proportion (50.994\%) was considered to be caused by LD [39]. We estimated $r^{2}$ at various distances to represent LD degree. The mean value of $r^{2}$ calculated for adjacent SNPs in this analysis was 0.557 which was similar to the result that Stratz et al. (2014) estimated in Piétrain pigs [40]. In addition, based on the value of $r^{2}$, the mean LD extent can be extended to a distance of $5 \mathrm{Mb}$, suggesting that LD can help form patterns of the short $\mathrm{ROH}$. As for intermediate and long $\mathrm{ROHs}$ that exceed the range of LD extent, they should were broken in the process of recombination, but did not, suggesting that they are supposed to be shaped by other factors [4]. To some extent, the factors like founder effects, genetic drift further increase the difficulty of exploring the ROH formation mechanism.

In population genetics, the decline rate of linkage disequilibrium and the linkage map distance can be used to infer population history and recent effective population size [41]. First, we calculate $\mathrm{Ne}$ under the assumption that $1 \mathrm{cM}$ approximate to $1 \mathrm{Mb}$ in physical distance following the previous study [31], and the result under this approximation was show in Table S3. In theory, this assumption may bias the value of $\mathrm{Ne}$ and affect the estimation accuracy, because different chromosomes have diverse linkage conditions due to their distinct physical and genetic distance. Corbin et al. proposed that the assumption that $1 \mathrm{cM}$ approximate to $1 \mathrm{Mb}$ in physical distance would result in lack of consistency for $\mathrm{Ne}$ estimated [41]. Therefore, the physical distance to genetic distance conversion rates were recalculated based on physical chromosome length and chromosome's genetic length in this study. We found that each chromosome possesses specific linkage condition, while the decline tendency was identical. In addition, Corbin et al. presented that estimation of $N e$ would be very sensitive and the result would be unreliable when generations $<7$. Hence, our estimation of $N e$ process terminated at 10 generations. We observed that $\mathrm{Ne}$ decreased gradually over generations, implying the decline of genetic variations in the long-term evolutionary process. Combining with the prevalence of $\mathrm{ROH}$ and numerous short $\mathrm{ROH}$ in this analysis, it suggested that the decrease of effective population size, as a signal of decline in genetic diversity, can also reflect high levels of homozygosity indirectly.

It is universally considered that inbreeding was an important factor affecting the pattern of homozygosity. In conventional breeding without available marker data, the inbreeding coefficient, $F$, was estimated through pedigree record, following a principle that an individual transmits an allele to an offspring with $50 \%$ probability all the time. However, in the transport process, meiosis was full of randomness with a large stochastic variance. Furthermore, in realistic breeding, it's common that pedigree record was incomplete or missing. Therefore, it was difficult to trace back the relationship between ancestors and distant parents, which has also become a vital factor affecting the accuracy of inbreeding estimate. This inaccuracy led to the weak correlation between pedigree-based inbreeding coefficients and genomic inbreeding coefficients as we observed.

In recent years, the inbreeding coefficient based on $\mathrm{ROH}$ has received more attention, and it was considered to be an accurate estimator to control the probability of inbreeding [5,42]. Compared with $F_{R O H}$, another genomic inbreeding estimator $F_{H O M}$ takes all of the homozygote into account, including separate single locus and homozygous regions. In that case, it will confound all of the history events in experimental population. At the same time, it will increase errors and biases caused by homozygotes generated by random recombination. On the contrary, $F_{R O H}$ could exclude accidental errors though removing single homozygous and quite short segments. In addition, it has been used in animal genetic analysis [7]. For example, Zhang et al. employed ROH to calculated inbreeding coefficients in cattle population and investigated the distribution of functional variants [11]. Bosse et al. remarked on the impact of demography and recombination on the formation of $\mathrm{ROH}$ to master genome inbreeding [10]. Mastrangelo et al. utilized $F_{R O H}$ to improve mating systems in Italian sheep breeds [6]. Furthermore, based on several recent researches, the short $\mathrm{ROH}$ and intermediate $\mathrm{ROH}$ were more potentially result from LD and ancient inbreeding, whereas long ROH could represent the level of recent inbreeding more appropriately by excluding obstacle of LD and random effects $[8,43,44]$. However, the size of boundary between classes was specific to different populations and breeds. Thus, it is more feasible to use total $\mathrm{ROH}$ instead of long $\mathrm{ROH}$ to estimate level of inbreeding. 
In this study, we identified $16 \mathrm{ROH}$ core regions where homozygous rate are pretty high for a specific population, many previous studies revealed that those homozygous segments had a major impact on gene mapping and disease [45-47]. Through sequence alignment in Pig QTLdb and gene annotation, we noticed that most of the segments harbored genes which could regulate important biologic functions of Piétrain and most of them may have an impact in economic traits. In this analysis, those regions were mostly linked with meat and carcass traits in Pig QTLdb, for example, QTL:22,293 harbored in one core region of $\mathrm{ROH}$ was related with average backfat thickness. In addition, a great part of them was relevant to production traits, like QTL:27977, a location associated with feed conversion ratio. In addition, there were several QTLs associated with reproduction traits, such as QTL:18325, a location expression in sperm motility. In addition, some of the core ROH regions also harbored QTLs related to exterior, like QTL:32743, associated with breed's coat color. Among them, we noticed several functional related genes in basic biologic processes, such as SLC35F1, a gene played a key role in controlling heat rate; $B 3 G A T 2$, was involved in cellular migration and adhesion in the nervous system; $D C B L D 1, L M B R D 1$ and $O M A 1$, all participated in compound integral component of membrane. In addition, we also noticed some genes which are related with Piétrain economical traits: MRAP2 can regulate the energy homeostasis machinery; $C L G N$, an important modulator in spermatogenesis and infertility. As terminal sires in pig industry, Piétrain pig was subjected to high-intensity artificial selection for a long time. Moreover, these observations are consistent with the expectation that homozygosity is associated with some biologic function and important economic traits affected by positive selection. After long-term positive selection, especially more recent artificial selection, regulatory regions that control the important economic traits would be highly homogenous because of directional selection. In other words, those specific regions are easier to be exposed in $\mathrm{ROH}$ core regions. Those observed phenomena indicate that positive selection is a significant force shaping patterns of homozygosity in the process of evolution, and the high-frequency $\mathrm{ROH}$ can contribute to exploit potential target genes of human-imposed selection.

\section{Conclusions}

In summary, this study investigated the patterns of runs of homozygosity, LD, effective population size and inbreeding coefficients, which provided a clear understanding of how diversity evolved in Piétrain pigs. The decrease of effective population size can mirror artificial selection in breeding process and the recession of genetic diversity. This phenomenon also proves the formation of ROH. Moreover, several genes associated with production traits were found overlapping with $\mathrm{ROH}$ regions. The high relationship between inbreeding coefficients $\left(F_{H O M}\right)$ based on homozygous genotypes and the inbreeding coefficients $\left(F_{R O H}\right)$ based on $\mathrm{ROH}$ exposes that the proportion of $\mathrm{ROH}$ has an instruction sense in assessing the population's level of inbreeding. Thus, using genomic information to detect $\mathrm{ROH}$ is a powerful method for estimating population inbreeding, especially in assessing the level of inbreeding where pedigrees records were incomplete or missing. Furthermore, the categories of ROHs may be related with the generations on the time frame, short $\mathrm{ROH}$ more reflects ancient inbreeding, while long $\mathrm{ROH}$ involves in recent inbreeding. Overall, the investigation of $\mathrm{ROH}$ patterns provides a helpful reference for selection and assortative mating in modern inbreeding and points an original direction for research of population genetic structure.

Supplementary Materials: The following are available online at http://www.mdpi.com/2073-4425/11/5/577/s1, Figure S1: Relationship between genomic inbreeding coefficients and pedigreed-based inbreeding coefficients; Table S1: Pedigree record in Piétrain pigs, Table S2: A list of 127 genes overlapping with the core runs of homozygosity $(\mathrm{ROH})$ regions in Piétrain pig, Table S3: Effective population size over generations for Piétrain pigs estimated based on the assumption that $1 \mathrm{cM} \approx 1 \mathrm{Mb}$.

Author Contributions: Data curation: X.L., S.Z. (Shuhong Zhao); funding acquisition: Y.M., S.Z. (Shuhong Zhao); project administration: Y.M.; supervision: S.Z. (Shuhong Zhao); writing-original draft: H.Z.; writing-review \& editing: Y.M., S.Z. (Shuhong Zhao), Data analysis: H.Z., S.Z. (Saixian Zhang), K.Z., X.P., S.X. All authors have read and agreed to the published version of the manuscript. 
Funding: This work was supported by National Natural Science Foundation of China [No.31790414 and No.31601916], the National Swine Industry Technology System [No. CARS-35] and the Fundamental Research Funds for the Central Universities.

Acknowledgments: We would like to express our sincere gratitude to the whole team at Laboratory of Agricultural Animal Genetics, Breeding, and Reproduction for helping to collect the samples.

Conflicts of Interest: The authors declare no competing financial interests.

\section{References}

1. Gorssen, W.; Meyermans, R.; Buys, N.; Janssens, S. SNP genotypes reveal breed substructure, selection signatures and highly inbred regions in Pietrain pigs. Anim. Genet. 2020, 51, 32-42. [CrossRef] [PubMed]

2. Porter, V. Pigs: A Handbook to the Breeds of the World; Comstock Publishing Associates: Ithaca, NY, USA, 1993; Volume 1, pp. 129-130.

3. Gibson, J.; Morton, N.E.; Collins, A. Extended tracts of homozygosity in outbred human populations. Hum. Mol. Genet. 2006, 15, 789-795. [CrossRef] [PubMed]

4. Pemberton, T.J.; Absher, D.; Feldman, M.W.; Myers, R.M.; Rosenberg, N.A.; Li, J.Z. Genomic patterns of homozygosity in worldwide human populations. Am. J. Hum. Genet. 2012, 91, 275-292. [CrossRef] [PubMed]

5. Keller, M.C.; Visscher, P.M.; Goddard, M.E. Quantification of inbreeding due to distant ancestors and its detection using dense single nucleotide polymorphism data. Genetics 2011, 189, 237-249. [CrossRef] [PubMed]

6. Mastrangelo, S.; Ciani, E.; Sardina, M.T.; Sottile, G.; Pilla, F.; Portolano, B. Runs of homozygosity reveal genome-wide autozygosity in Italian sheep breeds. Anim. Genet. 2018, 49, 71-81. [CrossRef] [PubMed]

7. Purfield, D.C.; Berry, D.P.; McParland, S.; Bradley, D.G. Runs of homozygosity and population history in cattle. BMC Genet. 2012, 13, 70. [CrossRef]

8. Marras, G.; Gaspa, G.; Sorbolini, S.; Dimauro, C.; Ajmone-Marsan, P.; Valentini, A.; Williams, J.L.; Macciotta, N.P. Analysis of runs of homozygosity and their relationship with inbreeding in five cattle breeds farmed in Italy. Anim. Genet. 2015, 46, 110-121. [CrossRef]

9. Mastrangelo, S.; Tolone, M.; Di Gerlando, R.; Fontanesi, L.; Sardina, M.T.; Portolano, B. Genomic inbreeding estimation in small populations: Evaluation of runs of homozygosity in three local dairy cattle breeds. Animal 2016, 10, 746-754. [CrossRef]

10. Bosse, M.; Megens, H.J.; Madsen, O.; Paudel, Y.; Frantz, L.A.; Schook, L.B.; Crooijmans, R.P.; Groenen, M.A. Regions of homozygosity in the porcine genome: Consequence of demography and the recombination landscape. PLoS Genet. 2012, 8, e1003100. [CrossRef]

11. Zhang, Q.; Guldbrandtsen, B.; Bosse, M.; Lund, M.S.; Sahana, G. Runs of homozygosity and distribution of functional variants in the cattle genome. BMC Genom. 2015, 16, 542. [CrossRef]

12. Szmatoła, T.; Gurgul, A.; Ropka-Molik, K.; Jasielczuk, I.; Zabek, T.; Bugno, M. Characteristics of runs of homozygosity in selected cattle breeds maintained in Poland. Livest. Sci. 2016, 188, 72-80. [CrossRef]

13. Purfield, D.C.; McParland, S.; Wall, E.; Berry, D.P. The distribution of runs of homozygosity and selection signatures in six commercial meat sheep breeds. PLoS ONE 2017, 12, e0176780. [CrossRef] [PubMed]

14. Kim, E.S.; Cole, J.B.; Huson, H.; Wiggans, G.R.; Van Tassell, C.P.; Crooker, B.A.; Liu, G.; Da, Y.; Sonstegard, T.S. Effect of artificial selection on runs of homozygosity in U.S. Holstein cattle. PLoS ONE 2013, 8, e80813. [CrossRef] [PubMed]

15. Pryce, J.E.; Haile-Mariam, M.; Goddard, M.E.; Hayes, B.J. Identification of genomic regions associated with inbreeding depression in Holstein and Jersey dairy cattle. Genet. Sel. Evol. 2014, 46, 71. [CrossRef]

16. Lencz, T.; Lambert, C.; DeRosse, P.; Burdick, K.E.; Morgan, T.V.; Kane, J.M.; Kucherlapati, R.; Malhotra, A.K. Runs of homozygosity reveal highly penetrant recessive loci in schizophrenia. Proc. Natl. Acad. Sci. USA 2007, 104, 19942-19947. [CrossRef]

17. Balmain, A. Cancer: New-age tumour suppressors. Nature 2002, 417, 235-237. [CrossRef]

18. Ismail, J.; Jafar, T.H.; Jafary, F.H.; White, F.; Faruqui, A.M.; Chaturvedi, N. Risk factors for non-fatal myocardial infarction in young South Asian adults. Heart 2004, 90, 259-263. [CrossRef]

19. Garrod, A.E. The Incidence of Alkaptonuria: A Study in Chemical Individuality. Lancet 1902, 160, 1616-1620. [CrossRef] 
20. Woods, C.G.; Cox, J.; Springell, K.; Hampshire, D.J.; Mohamed, M.D.; McKibbin, M.; Stern, R.; Raymond, F.L.; Sandford, R.; Malik Sharif, S.; et al. Quantification of homozygosity in consanguineous individuals with autosomal recessive disease. Am. J. Hum. Genet. 2006, 78, 889-896. [CrossRef]

21. Wright, S. Wright s. Size of population and breeding structure in relation to evolution. Science 1938, 87, 430-431.

22. Sved, J.A. Linkage disequilibrium and homozygosity of chromosome segments in finite populations. Theor. Popul. Biol. 1971, 2, 125-141. [CrossRef]

23. Hayes, B.J.; Visscher, P.M.; McPartlan, H.C.; Goddard, M.E. Novel multilocus measure of linkage disequilibrium to estimate past effective population size. Genome Res. 2003, 13, 635-643. [CrossRef]

24. Tenesa, A.; Navarro, P.; Hayes, B.J.; Duffy, D.L.; Clarke, G.M.; Goddard, M.E.; Visscher, P.M. Recent human effective population size estimated from linkage disequilibrium. Genome Res. 2007, 17, 520-526. [CrossRef]

25. Villa-Angulo, R.; Matukumalli, L.K.; Gill, C.A.; Choi, J.; Van Tassell, C.P.; Grefenstette, J.J. High-resolution haplotype block structure in the cattle genome. BMC Genet. 2009, 10, 19. [CrossRef]

26. Corbin, L.J.; Blott, S.C.; Swinburne, J.E.; Vaudin, M.; Bishop, S.C.; Woolliams, J.A. Linkage disequilibrium and historical effective population size in the Thoroughbred horse. Anim. Genet. 2010, 41, 8-15. [CrossRef]

27. Shin, D.; Won, K.H.; Kim, S.H.; Kim, Y.M. Extent of linkage disequilibrium and effective population size of Korean Yorkshire swine. Asian-Australas. J. Anim. Sci. 2018, 31, 1843-1851. [CrossRef]

28. Purcell, S.; Neale, B.; Todd-Brown, K.; Thomas, L.; Ferreira, M.A.; Bender, D.; Maller, J.; Sklar, P.; de Bakker, P.I.; Daly, M.J.; et al. PLINK: A tool set for whole-genome association and population-based linkage analyses. Am. J. Hum. Genet. 2007, 81, 559-575. [CrossRef]

29. McQuillan, R.; Leutenegger, A.L.; Abdel-Rahman, R.; Franklin, C.S.; Pericic, M.; Barac-Lauc, L.; Smolej-Narancic, N.; Janicijevic, B.; Polasek, O.; Tenesa, A.; et al. Runs of homozygosity in European populations. Am. J. Hum. Genet. 2008, 83, 359-372. [CrossRef] [PubMed]

30. Qanbari, S.; Hansen, M.; Weigend, S.; Preisinger, R.; Simianer, H. Linkage disequilibrium reveals different demographic history in egg laying chickens. BMC Genet. 2010, 11, 103. [CrossRef] [PubMed]

31. Uimari, P.; Tapio, M. Extent of linkage disequilibrium and effective population size in Finnish Landrace and Finnish Yorkshire pig breeds. J. Anim. Sci. 2011, 89, 609-614. [CrossRef]

32. Srisai, D.; Yin, T.C.; Lee, A.A.; Rouault, A.A.J.; Pearson, N.A.; Grobe, J.L.; Sebag, J.A. MRAP2 regulates ghrelin receptor signaling and hunger sensing. Nat. Commun. 2017, 8, 713. [CrossRef]

33. Shiba, T.; Kakuda, S.; Ishiguro, M.; Morita, I.; Oka, S.; Kawasaki, T.; Wakatsuki, S.; Kato, R. Crystal structure of GlcAT-S, a human glucuronyltransferase, involved in the biosynthesis of the HNK-1 carbohydrate epitope. Proteins 2006, 65, 499-508. [CrossRef] [PubMed]

34. Rutsch, F.; Gailus, S.; Miousse, I.R.; Suormala, T.; Sagne, C.; Toliat, M.R.; Nurnberg, G.; Wittkampf, T.; Buers, I.; Sharifi, A.; et al. Identification of a putative lysosomal cobalamin exporter altered in the cblF defect of vitamin B12 metabolism. Nat. Genet. 2009, 41, 234-239. [CrossRef]

35. Nolte, I.M.; Wallace, C.; Newhouse, S.J.; Waggott, D.; Fu, J.; Soranzo, N.; Gwilliam, R.; Deloukas, P.; Savelieva, I.; Zheng, D.; et al. Common genetic variation near the phospholamban gene is associated with cardiac repolarisation: Meta-analysis of three genome-wide association studies. PLoS ONE 2009, 4, e6138. [CrossRef]

36. Schmoker, A.M.; Weinert, J.L.; Kellett, K.J.; Johnson, H.E.; Joy, R.M.; Weir, M.E.; Ebert, A.M.; Ballif, B.A. Dynamic multi-site phosphorylation by Fyn and Abl drives the interaction between CRKL and the novel scaffolding receptors DCBLD1 and DCBLD2. Biochem. J. 2017, 474, 3963-3984. [CrossRef]

37. Rainbolt, T.K.; Lebeau, J.; Puchades, C.; Wiseman, R.L. Reciprocal degradation of YME1L and OMA1 adapts mitochondrial proteolytic activity during stress. Cell Rep. 2016, 14, 2041-2049. [CrossRef]

38. Van Lith, M.; Karala, A.R.; Bown, D.; Gatehouse, J.A.; Ruddock, L.W.; Saunders, P.T.; Benham, A.M. A developmentally regulated chaperone complex for the endoplasmic reticulum of male haploid germ cells. Mol. Biol. Cell 2007, 18, 2795-2804. [CrossRef] [PubMed]

39. Frazer, K.A.; Ballinger, D.G.; Cox, D.R.; Hinds, D.A.; Stuve, L.L.; Gibbs, R.A.; Belmont, J.W.; Boudreau, A.; Hardenbol, P.; Leal, S.M.; et al. A second generation human haplotype map of over 3.1 million SNPs. Nature 2007, 449, 851-861. [CrossRef] [PubMed]

40. Stratz, P.; Wimmers, K.; Meuwissen, T.H.; Bennewitz, J. Investigations on the pattern of linkage disequilibrium and selection signatures in the genomes of German Pietrain pigs. J. Anim. Breed. Genet. 2014, 131, 473-482. [CrossRef] 
41. Corbin, L.J.; Liu, A.Y.; Bishop, S.C.; Woolliams, J.A. Estimation of historical effective population size using linkage disequilibria with marker data. J. Anim. Breed. Genet. 2012, 129, 257-270. [CrossRef]

42. Sölkner, J.; Ferenčaković, M.; Schwarzenbacher, H.; Gredler, B.; Fürst, C.; Čurik, I. Genomic Metrics of Individual Autozygosity, Applied to a Cattle Population. In Proceedings of the 61st Annual Conference of the European Association for Animal Production, Heraklion, Greece, 23-27 August 2010. Session code G38.03.

43. Zavarez, L.B.; Utsunomiya, Y.T.; Carmo, A.S.; Neves, H.H.; Carvalheiro, R.; Ferencakovic, M.; Perez O’Brien, A.M.; Curik, I.; Cole, J.B.; Van Tassell, C.P.; et al. Assessment of autozygosity in Nellore cows (Bos indicus) through high-density SNP genotypes. Front. Genet. 2015, 6, 5. [CrossRef]

44. Peripolli, E.; Stafuzza, N.B.; Munari, D.P.; Lima, A.L.F.; Irgang, R.; Machado, M.A.; Panetto, J.; Ventura, R.V.; Baldi, F.; da Silva, M. Assessment of runs of homozygosity islands and estimates of genomic inbreeding in Gyr (Bos indicus) dairy cattle. BMC Genom. 2018, 19, 34. [CrossRef]

45. Broman, K.W.; Weber, J.L. Long homozygous chromosomal segments in reference families from the Centre d'Etude du Polymorphisme Humain. Am. J. Hum. Genet. 1999, 65, 1493-1500. [CrossRef] [PubMed]

46. Scott, E.M.; Halees, A.; Itan, Y.; Spencer, E.G.; He, Y.; Azab, M.A.; Gabriel, S.B.; Belkadi, A.; Boisson, B.; Abel, L.; et al. Characterization of Greater Middle Eastern genetic variation for enhanced disease gene discovery. Nat. Genet. 2016, 48, 1071-1076. [CrossRef] [PubMed]

47. Lu, Y.H.; Wang, B.H.; Xia, W.; Mo, X.B.; Wu, L.F.; Zhu, X.W.; He, P.; Xie, F.F.; Lu, X.; Deng, F.Y.; et al. The distribution and functional relevance analysis of runs of homozygosity (ROHs) in Chinese Han female population. Mol. Genet. Genom. 2018, 293, 197-206. [CrossRef] [PubMed]

(C) 2020 by the authors. Licensee MDPI, Basel, Switzerland. This article is an open access article distributed under the terms and conditions of the Creative Commons Attribution (CC BY) license (http://creativecommons.org/licenses/by/4.0/). 